\title{
EHMTI-0045. The succession of aura and headache: a prospective diary-based study
}

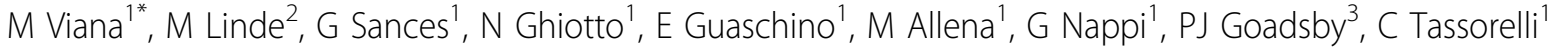 \\ From 4th European Headache and Migraine Trust International Congress: EHMTIC 2014 \\ Copenhagen, Denmark. 18-21 September 2014
}

\section{Introduction}

Evaluation of clinical characteristic of migraine with aura, such as timing of succession between aura and headache, is important as it might give us an insight in migraine with aura pathophysiology. At the best of our knowledge no study assessed with a prospective diary specifically the time of onset/end of aura and headache. Few prospective studies inquired generally about the presence of one symptom (aura or headache) during the other one (Hansen et al 2012).

\section{Aims}

To evaluate the temporal relationship between aura onset/end and headache with a prospective diary-based study.

\section{Methods}

We recruited 136 consecutive patients affected by nonhemiplegic migraine aura at the Headache Centers of Pavia and Trondheim. All the patients prospectively recorded the characteristics of three consecutive attacks in an ad hoc aura diary that included the time of onset and the end of each aura symptoms and headache.

\section{Results}

Of the 136 patients recruited so far, 44 completed the diaries during three consecutive auras for a cumulative number of 132 auras recorded. In 14 attacks, headache (HA) did not follow aura, and in 26 attacks HA was present but we do not have any information about its onset. Of the remaining 92 auras, in 9 (10\%) HA started before aura, in 10 (11\%) HA started simultaneously with aura; in 28 (30\%) HA started during aura, in $13(14 \%)$ auras HA started when aura stopped, in 32 (35\%) HA

${ }^{1}$ Headache Science Center, C. Mondino National Neurological Institute, Pavia, Italy

Full list of author information is available at the end of the article started after a free interval of time after the end of aura (see Figure).

\section{Conclusions}

The headache phase of migraine with aura may either start before, simultaneously, during or after, the end of aura.

No conflict of interest.

\section{Authors' details}

Headache Science Center, C. Mondino National Neurological Institute, Pavia, Italy. ${ }^{2}$ Norwegian National Headache Centre Department of Neuroscience, Norwegian University of Science and Technology, Trondheim, Norway. ${ }^{3}$ Headache Group - NIHR-Wellcome Trust Clinical Research Facility, King's College London, London, UK.

Published: 18 September 2014

doi:10.1186/1129-2377-15-S1-D73

Cite this article as: Viana et al:: EHMTI-0045. The succession of aura and headache: a prospective diary-based study. The Journal of Headache and Pain 2014 15(Suppl 1):D73. (c) 2014 Viana et al; licensee Springer. This is an Open Access article distributed under the terms of the Creative Commons Attribution License (http://creativecommons.org/licenses/by/2.0), which permits unrestricted use, distribution, and reproduction in any medium, provided the original work is properly cited.
Submit your manuscript to a SpringerOpen ${ }^{\bullet}$ journal and benefit from:

- Convenient online submission

Rigorous peer review

- Immediate publication on acceptance

- Open access: articles freely available online

- High visibility within the field

- Retaining the copyright to your article

Submit your next manuscript at $>$ springeropen.com 